\title{
Breast cancer animal models: Rasa1 knockout.
}

\author{
Raquel Sánchez-Baltasara, Angustias Page, Isabel Ojeda-Pérez, Claudia Gil-Pitarch, \\ Manuel Navarro, Ángel Ramírez
}

CIEMAT-Instituto de Investigación Hospital 12 de Octubre.

a. raquel.sanchez@externos.ciemat.es

IV Congreso de Señalización Celular, SECUAH 2019.

20-22 de marzo, 2019. Universidad de Alcalá. Alcalá de Henares, Madrid. España

Sesión de paneles.

Keywords: Cáncer de mama; Rasa1; Tpr53; CRISPR/Cas9

\begin{abstract}
El cáncer de mama es el tipo de tumor que ocupa el primer puesto en incidencia en la población femenina mundial y es uno de los que mayor mortalidad causa. A pesar de que es frecuente encontrar mutaciones en los genes clásicos de la familia de Ras en otros tipos tumorales, no lo es en cáncer de mama, aunque la vía se encuentra frecuentemente sobreactivada en algunos subtipos como los triple negativos o basales. Estudios previos en nuestro laboratorio sugieren que esto puede deberse a la pérdida alélica de RASA1 en concomitancia con mutaciones en el gen TP53, eventos frecuentes en estos subtipos tumorales que son los más agresivos y de peor pronóstico. Por ello, hemos decidido llevar a cabo un estudio en profundidad de los mecanismos moleculares que llevan al desarrollo y/o progresión del cáncer de mama como consecuencia de la alteración de estos dos genes. En consecuencia, se planteó la generación de modelos animales deficientes en Rasa1 en combinación con mutaciones en Trp53 con el objetivo de confirmar la colaboración de la activación de la vía de Ras y p53 como causante de cáncer de mama. Para el desarrollo de estos modelos animales modificados genéticamente se empleó la tecnología CRISPR/Cas9. Para ello, se diseñó una pareja de guías específicas para el gen Rasa1 con el objetivo de utilizarlas mediante dos aproximaciones diferentes. En primer lugar, con el objetivo futuro de realizar el aloinjerto de células de glándula mamaria electroporadas con las guías diseñadas para Rasa1 (e infectadas con un vector lentiviral para la sobreexpresión de una forma mutada de p53), se realizó una puesta a punto extrayendo y purificando estas células de hembras donadoras e infectándolas con un vector lentiviral que expresa la proteína GFP para trasplantarlas en la almohadilla grasa desepitelizada de hembras receptoras. Por otro lado, se empleó la tecnología CRISPR/Cas9 para realizar la edición del gen Rasa1 en estadio embrionario. Las guías específicas para este gen se introdujeron en los zigotos junto con la Cas9 en forma de ribononucleoproteína mediante electroporación por dos métodos: iGonad ("Oviductal Nucleic Acids Delivery") o ZEN ("Zygote Electroporation of Nucleases"). En el modelo de aloinjerto se observó una reconstitución del epitelio de la glándula mamaria con las células trasplantadas a 2 meses post-trasplante, verificando la utilidad de esta aproximación para la generación de nuestro modelo. Respecto a la electroporación de los zigotos, aunque con el método iGonad no se vio edición en ninguno de los casos, con el método ZEN se consiguió un $75 \%$ de edición, donde en más del $80 \%$ de estos animales se observó un cambio de expresión de la proteína RASA1. En conclusión, tanto la aproximación del aloinjerto en la glándula mamaria como la utilización del método ZEN para la generación de modelos animales modificados genéticamente con la tecnología CRISPR/Cas9 para el gen Rasa1, pueden ser una buena aproximación para el estudio de la implicación de este gen en el cáncer de mama.
\end{abstract}

Citation: Sánchez-Baltasar, Raquel; Page, Angustias; Ojeda-Pérez, Isabel; Gil-Pitarch, Claudia;

Navarro, Manuel; Ramírez, Ángel (2019) Breast cancer animal models: Rasa1 knockout. Proceedings of the IV

Congreso de Señalización Celular, SECUAH 2019. 20-22 de marzo, 2019. Universidad de Alcalá. Alcalá de Henares, Madrid. España. Sesión de paneles. dianas 8 (1): e201903p05. ISSN 1886-8746 (electronic) journal.dianas.e201903p05 http://www3.uah.es/dianas?e201903p05. URI http://hdl.handle.net/10017/15181

Copyright: @ Sánchez-Baltasar R, Page A, Ojeda-Pérez I, Gil-Pitarch C, Navarro M, Ramírez. Some rights reserved. This is an open-access work licensed under a Creative Commons Attribution-NonCommercialNoDerivatives 4.0 International License. http://creativecommons.org/licenses/by-nc-nd/4.0/ 